\title{
Monitoring of Aerosol Pollution of Snow Cover with Ground Based Observation Data and Satellite Information
}

\author{
Anatoly A. Lezhenin*a, \\ Tatyana V. Yaroslavtseva ${ }^{\mathrm{b}}$ and Vladimir F. Raputa ${ }^{\mathrm{a}}$ \\ ${ }^{a}$ Institute of Computational Mathematics \\ and Mathematical Geophysics SB RAS \\ 6 Akademika Lavrenteva, Novosibirsk, 630090, Russia \\ ${ }^{b}$ Novosibirsk Scientific Researchinstitute of Hygiene \\ Rospotrebnadzora \\ 7 Parhomenko, Novosibirsk, 630108, Russia
}

Received 11.02.2016, received in revised form 13.03.2016, accepted 18.03.2016

With data on the monitoring of snow cover pollution and satellite images an analysis of the sedimentation of polluted substances from high-altitude chimneys of the Iskitimsky cement plant is carried out. On the basis of the solution of a semi-empirical equation for the transfer and diffusion of substance in the atmosphere, a numerical reconstruction of the dust pollution field in the vicinity of the enterprise is made. A possibility of using satellite information to assess the areas of pollution which out snow precipitation formed in time intervals from several days to several weeks is shown.

Keywords: atmosphere, aerosol, pollution of snow cover, numerical modeling, satellite images.

Citation: Lezhenin A.A., Yaroslavtseva T.V., Raputa V.F. Monitoring of aerosol pollution of snow cover with ground based observation data and satellite information, J. Sib. Fed. Univ. Eng. technol., 2016, 9(7), 950-959. DOI: 10.17516/1999-494X2016-9-7-950-959.

(C) Siberian Federal University. All rights reserved

* Corresponding author E-mail address: lezhenin@ommfao.sscc.ru 


\title{
Мониторинг аэрозольного
}

\section{загрязнения снежного покрова на основе наземной и спутниковой информации}

\author{
А.А. Леженин ${ }^{a}$ Т.В. Ярославцева ${ }^{6}$, В.Ф. Рапута ${ }^{a}$ \\ ${ }^{a}$ Институт вычислительной математики \\ и математической геофизики СО РАН \\ Россия, 630090, Новосибирск, пр. Лаврентьева, 6 \\ ${ }^{6}$ Новосибирский институт гигиены Роспотребнадзора \\ Россия, 630108, Новосибирск, ул. Пархоменко, 7
}

С использованием данных мониторинга загрязнения снежного покрова и спутниковых снимков проведен анализ полей выпадения взвещенных веществ от высотных труб Искитимского иементного завода. На основе решения полуэмпирического уравнения переноса и диффузии примесей в атмосфере выполнена численная реконструкция пылевого загрязнения окрестностей предприятия. Для периодов отсутствия снегопадов показана возможность использования спутниковой информации при оценке ореолов загрязнений, формирующихся в интервалах времени от нескольких дней до нескольких недель.

Ключевые слова: атмосфера, аэрозоль, загрязнение снежного покрова, численное моделирование, спутниковые наблюдения.

\section{Введение}

Для описания процессов переноса атмосферных загрязнителей широко используются методы математического моделирования [1-3]. При наличии необходимой входной информации применение этих методов является достаточно эффективным. Однако в реальных условиях всегда существует проблема неполноты входных данных. В этом случае моделирование процессов распространения примесей существенно усложняется, требует использования разносторонней информации о процессах загрязнения и проведения дополнительных теоретических и экспериментальных исследований.

Информация, получаемая с искусственных спутников Земли, позволяет визуализировать загрязнения атмосферы, растительного и снежного покрова вокруг городов и крупных промышленных предприятий [4-7]. Снежный покров на спутниковых снимках служит фоном, на котором можно наблюдать постепенное развитие загрязнения территорий. Этот эффект наглядно проявляется в периоды времени, когда отсутствуют выпадения снега, а также во время снеготаяния в конце зимнего сезона [7-10]. Следует отметить, что инструментальные исследования загрязнения атмосферного воздуха требуют значительных материальных затрат и их проведение, как правило, носит эпизодический характер. Более экономичные методы - использование природных планшетов (почвенный, растительный и снежный покровы), а также данных дистанционного зондирования Земли.

\section{Материалы и методы}

В зимние сезоны 2012/13 и 2013/14 гг. проводились мониторинговые исследования пылевого загрязнения снежного покрова в окрестностях цементного завода, расположенного в 
г. Искитим [11]. Город находится в юго-восточной части Новосибирской области в 55 км от областного центра - г. Новосибирска. С севера и востока к промплощадке предприятия примыкает р. Бердь. Основными источниками выброса неорганической пыли в атмосферу являются две близко расположенные 80 -метровые трубы с диаметрами 6 м.

Объектами исследования служили выбросы взвешенных веществ от стационарных источников ОАО «Искитимцемент», снежный покров на территории г. Искитим и за его пределами. Материалами исследований являлись отчёты ОАО «Искитимцемент» о выбросах в атмосферу загрязняющих веществ стационарными источниками в период 2012-2013 гг., результаты визуальных и спутниковых наблюдений и физико-химического анализа состава проб снеговой воды.

Маршруты отбора проб располагались по восьми румбам относительно основных источников выброса неорганической пыли. Точки наблюдений находились в пределах расстояний от 0,4 до 3 км. Отбор проб был произведён более чем в 40 точках. Это позволило провести детальный численный анализ процессов выпадений пыли от основных источников предприятия, установить количественные закономерности содержания осадка в снеге на различных направлениях выноса. На рис. 1 представлена схема отбора проб снега, расположение основных источников и метеостанции г. Искитима.

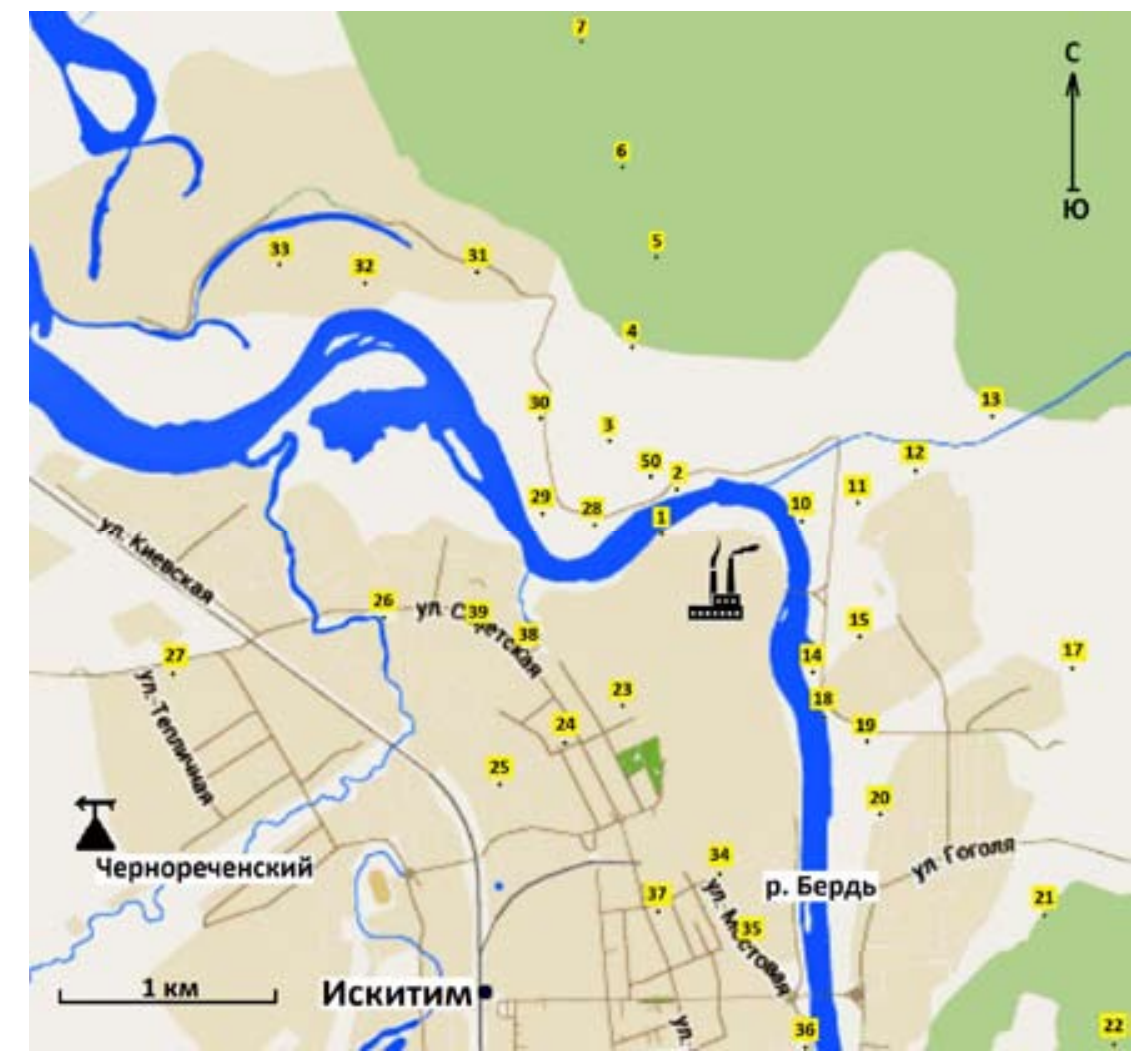

Рис. 1. Схема отбора проб снега: $\underset{\mathbf{n}}{\mathbf{n}}$ - основной источник выброса пыли; $\boldsymbol{\Sigma}_{- \text {положение метеостанции }}$ г. Искитима 
Таблица 1. Повторяемость направлений ветра на метеорологической станции г. Искитим в зимние периоды времени

\begin{tabular}{|l|c|c|c|c|c|c|c|c|c|}
\hline \multicolumn{1}{|c|}{ Направление ветра } & С & С3 & 3 & Ю3 & Ю & ЮВ & В & СВ & штиль \\
\hline $\begin{array}{l}\text { Повторяемость ветра в зимнем } \\
\text { сезоне 2012/13 г., \% }\end{array}$ & 1 & 5 & 16 & 30 & 29 & 7 & 2 & 1 & 9 \\
\hline $\begin{array}{l}\text { Повторяемость ветра с 30.01.14 по } \\
\text { 7.02.14, \% }\end{array}$ & 0 & 3 & 14 & 62 & 10 & 0 & 0 & 2 & 9 \\
\hline
\end{tabular}

Предварительный анализ данных измерений показал сильное защелачивание снеготалых вод. В пределах до 1,5 км от основных источников выбросов величина рН варьировалась от 9 до 12 ед. Преобладающие выпадения пыли произошли в северо-западном, северном и северовосточном направлениях от цементного завода.

Для проведения оценок распространения пылевого загрязнения снежного покрова в окрестностях цементного завода полезно использовать информацию о повторяемости направлений ветра в различные периоды времени. В табл. 1 приведены данные метеостанции о повторяемости направлений ветра за зимний сезон 2012/13 г. и за период времени с 30 января по 7 февраля 2014 г.

Промежутки времени, когда отсутствуют снегопады, удобны для анализа спутниковых наблюдений. С 30 января по 7 февраля 2014 г. метеостанция зафиксировала отсутствие выпадений снега. При этом в более 80 \% случаев преобладали слабые ветры (1-2 м/с). Штилевые условия наблюдались в $9 \%$ случаев.

\section{Модель реконструкции}

При расчете средней концентрации в приземном слое атмосферы определяющее значение имеют часто встречающиеся метеорологические условия. К ним относятся так называемые нормальные метеоусловия, для которых используется степенная аппроксимация скорости ветра и коэффициента вертикального турбулентного обмена [3]. В этом случае использование асимптотик полуэмпирического уравнения турбулентной диффузии и статистических свойств распределения скорости ветра и вертикального турбулентного обмена в приземном слое атмосферы позволяет выразить плотность выпадений полидисперсной примеси за длительный промежуток времени в виде следующей регрессионной зависимости $[12,13]$ :

$$
\bar{q}(r, \varphi)=\frac{\theta_{1}}{r^{1.5}} P\left(\varphi+180^{\circ}\right) \exp \left(-\frac{c}{r}\right) \int_{0}^{\infty} \frac{\omega^{-\theta_{2}} \exp \left(-\theta_{3} \omega\right)}{\Gamma(1+\omega)}\left(\frac{c}{r}\right)^{\omega} d \omega
$$

где $r, \varphi$ - полярные координаты; $P(\varphi)$ - приземная роза ветров; $\Gamma(m)$ - гамма-функция Эйлера; $c$ определяется высотой источника; параметры $\theta_{1}, \theta_{2}, \theta_{3}$ неотрицательны.

Исследование свойств функции (1) показывает, что она в интервале значений $r \in(0, \infty)$ достигает максимума в некоторой точке $r_{0}$, монотонно возрастает при $r \in\left(0, r_{0}\right)$, соответственно монотонно убывает в интервале значений $r \in\left(r_{0}, \infty\right)$ и стремится к нулю при $r \rightarrow 0, r \rightarrow \infty$. Оценка неизвестных параметров $\theta_{1}, \theta_{2}, \theta_{3}$, входящих в соотношение (1), проводится методом 
наименьших квадратов с использованием данных измерений плотности выпадений взвешенных веществ в точках местности. Следует также отметить, что величина $1,5 \cdot c$ соответствует величине расстояния, на котором достигается максимальная приземная концентрация слабооседающей примеси [3].

Замечание 1. Параметры $\theta_{2}, \theta_{3}$ зависят от характеристик дисперсного состава аэрозольной примеси и метеорологических условий. Данное обстоятельство позволяет существенно снизить количество опорных точек измерений при проведении оценивания выпадений примеси по другим радиальным относительно источника направлениям. В этом случае достаточно лишь провести переоценку параметра $\theta_{1}$, который, согласно [12], пропорционален мощности источника и изменение которого зависит от временного интервала повторяемости ветра в заданном направлении.

\section{Результаты}

В табл. 2 приведены результаты экспериментальных исследований выпадений взвешенных веществ в окрестностях цементного завода. Совместный анализ рис. 1 и данных табл. 2 показывает, что по всем исследованным направлениям выноса с увеличением расстояния от источника происходит монотонное убывание выпадений пыли.

На основе модели (1) проведена численная реконструкция поля выпадений. Показано существование устойчивых количественных закономерностей содержания пыли в снежном покрове по радиальным относительно основного источника направлениям. Восстановлено сум-

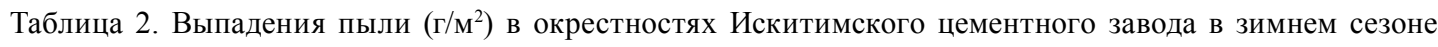
2012/13 г.

\begin{tabular}{|c|c|c|c|c|c|c|c|c|}
\hline Номер точки & 1 & 2 & 3 & 4 & 5 & 6 & 7 & 10 \\
\hline Расстояние от источника, км & 0.56 & 0.73 & 1.03 & 1.39 & 1.76 & 2.18 & 2.75 & 0.69 \\
\hline Плотность выпадений пыли, г/м² & 604.2 & 214.4 & 133.9 & 46.8 & 20.0 & 9.6 & 7.4 & 143.6 \\
\hline Номер точки & 11 & 12 & 13 & 14 & 15 & 17 & 18 & 19 \\
\hline Расстояние от источника, км & 0.92 & 1.2 & 1.62 & 0.46 & 0.66 & 1.6 & 0.58 & 0.79 \\
\hline Плотность выпадений пыли, г/м² & 58.7 & 34.1 & 14.1 & 103.4 & 54.1 & 15.9 & 76.6 & 49.4 \\
\hline Номер точки & 20 & 21 & 22 & 23 & 24 & 25 & 26 & 27 \\
\hline Расстояние от источника, км & 1.04 & 1.89 & 2.66 & 0.48 & 0.78 & 1.12 & 1.49 & 2.41 \\
\hline Плотность выпадений пыли, г/м² & 32.6 & 17.3 & 10.2 & 51.9 & 9.3 & 7.7 & 10.6 & 0.7 \\
\hline Номер точки & 28 & 29 & 30 & 31 & 32 & 33 & 34 & 35 \\
\hline Расстояние от источника, км & 0.76 & 0.97 & 1.28 & 1.97 & 2.23 & 2.57 & 0.99 & 1.34 \\
\hline Плотность выпадений пыли, г/м² & 521.0 & 408.6 & 162.7 & 74.4 & 63.3 & 35.7 & 22.7 & 23.2 \\
\hline Номер точки & 36 & 37 & 38 & 39 & 50 & & & \\
\hline Расстояние от источника, км & 2.09 & 1.2 & 0.83 & 1.05 & 0.81 & & & \\
\hline Плотность выпадений пыли, г/м² & 48.7 & 20.2 & 114.1 & 32.5 & 242.4 & & & \\
\hline
\end{tabular}


марное поле выпадений пыли и проведена оценка выбросов в атмосферу в рассматриваемом зимнем сезоне. Результаты численного моделирования представлены на рис. 2.

Оценивание параметров регрессии (1) проводилось по данным измерений твёрдого осадка примеси в снеге в точках северо-восточного направления с номерами 10, 11, 12. Было рассмотрено два варианта восстановления поля выпадений. В первом варианте использовались в соответствии с замечанием 1 данные измерений выпадений примеси на всех маршрутах пробоотбора. Во втором варианте была использована информация о зимней розе ветров и результаты оценивания параметров $\theta_{1}, \theta_{2}, \theta_{3}$.

На рис. 3 приведено сопоставление в точках отбора проб снега данных экспериментальных исследований с результатами восстановления по модели (1) плотности аэрозольных выпадений примесей. Анализ рис. 3 показывает, что результаты расчетов по первому варианту вполне

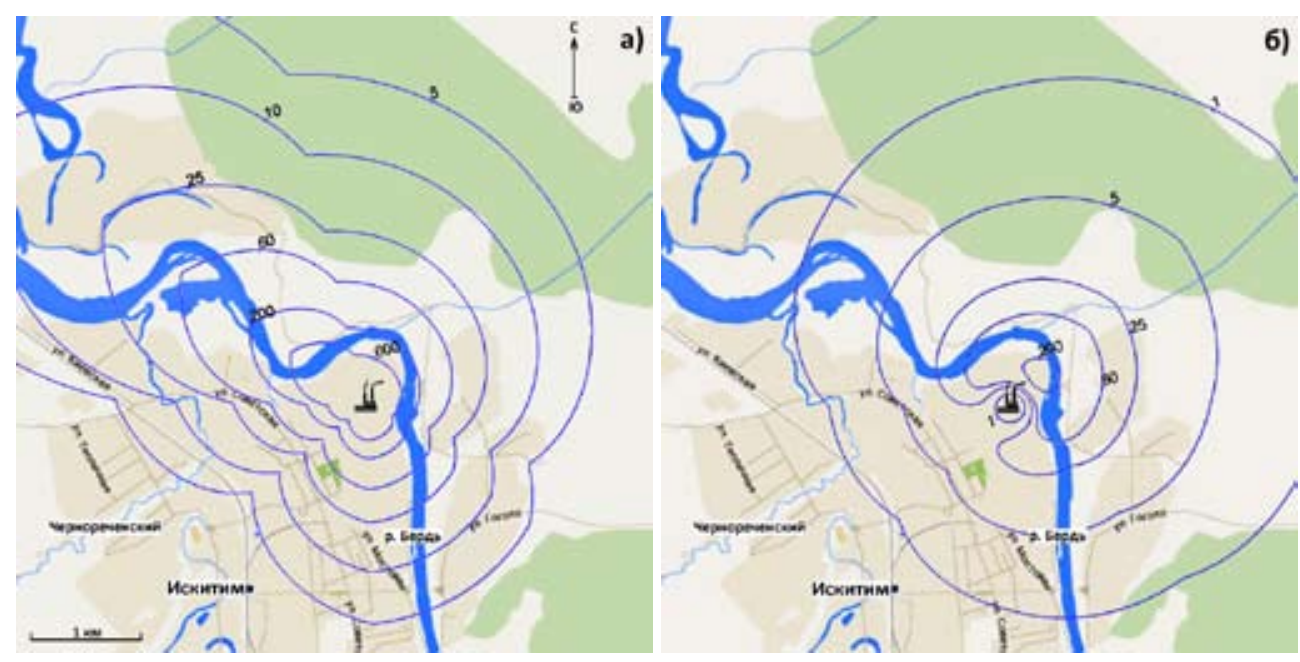

Рис. 2. Восстановленные на основе модели (1) поля плотности выпадений пыли (г/м²) по данным маршрутной снегосъёмки (а) и с использованием зимней розы ветров (б)

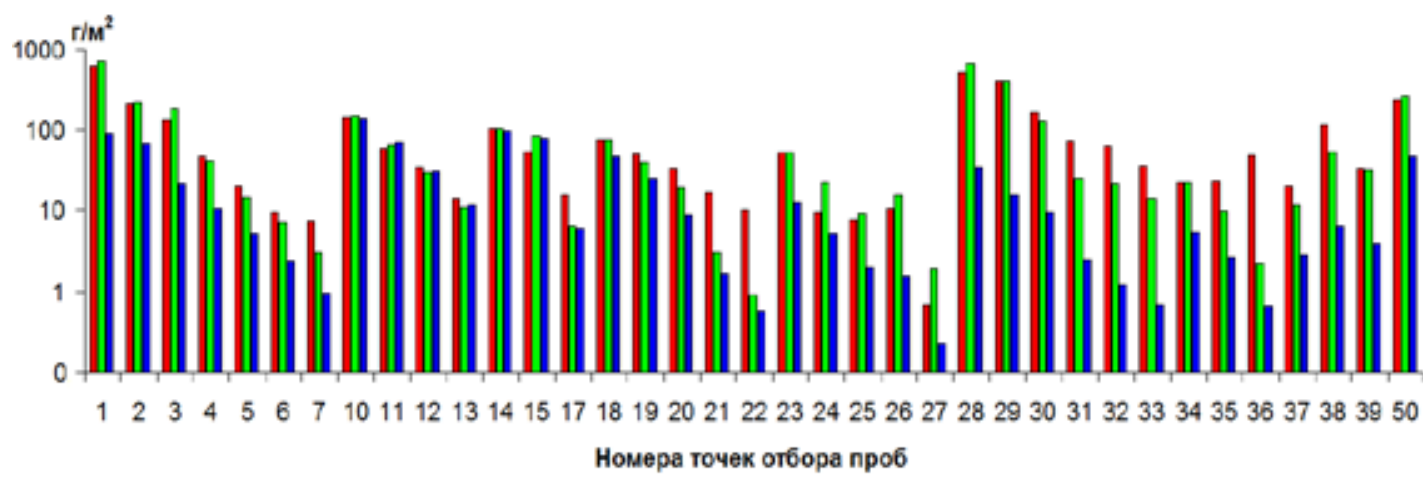

Рис. 3. Измеренные (๘) и восстановленные на основе зависимости (1) выпадения пыли $\left(\Gamma / \mathrm{M}^{2}\right)$ в точках отбора проб снега: (匚) - расчёт с использованием данных наблюдений со всех маршрутов отбора проб; (匹) - расчёт с использованием наблюдений в северо-восточном направлении и зимней розы ветров 2012/13 г. 


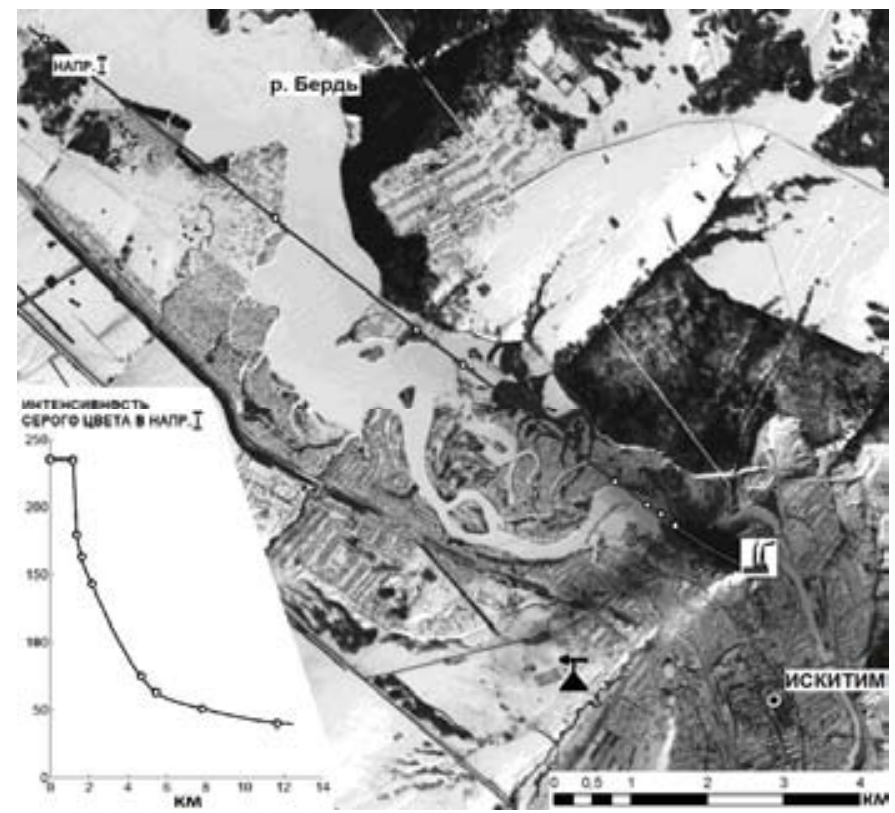

Рис. 4. Спутниковый снимок окрестностей Искитимского цементного завода от 7 февраля 2014 г. В левом нижнем углу - интенсивность изменения оттенков серого цвета в северо-западном направлении (направление I) от основных источников пылевых выбросов

удовлетворительно согласуются с данными наблюдений, в расчетах же по второму варианту расхождения весьма значительны.

Привлечение спутниковых наблюдений позволяет визуализировать пространственную картину поля выпадения пыли на снежный покров. На рис. 4 представлен снимок окрестностей Искитимского цементного завода с ИСЗ «Landsat-8» за 7 февраля 2014 г., взятый с сайта Сибирского центра ФГБУ «Научно-исследовательский центр космической гидрометеорологии «ПЛАНЕТА» ( http://www.rcpod.ru ).

На снимке отчетливо видна область интенсивного загрязнения снежного покрова в северо-западном направлении от источника. Метеорологическая станция, расположенная на расстоянии около 2 км от промышленной площадки предприятия, не фиксировала интенсивного выпадения снега в период с 30 января по 7 февраля 2014 г. Следовательно, основной шлейф загрязнения, видимый на космическом снимке, сформировался за этот период времени. Из табл. 1 следует, что в данный промежуток времени доминировали ветры западного (14 \%), юго-западного (62 \%) и южного (10 \%) направлений.

На рис. 4 явно прослеживается северо-западная ориентация пылевого выноса. Интенсивность изменения яркостных характеристик снежного покрова в этом направлении монотонно уменьшается с увеличением расстояния от источника загрязнения, что подтверждается также результатами наземного мониторинга.

\section{Обсуждение результатов}

Из анализа данных экспериментальных исследований и результатов моделирования, приведённых на рис. $2 a$ и в табл. 1 , следует, что основные выпадения пыли от высотных труб Иски-

$$
-956-
$$


тимского цементного завода произошли в направлении на северо-запад, вдоль долины р. Бердь. Исходя же из режима ветра, основные выносы пыли согласно рис. 26 следовало бы ожидать в северо-восточном направлении.

С другой стороны, спутниковые снимки загрязнения снежного покрова также подтверждают, что основные выпадения пыли наблюдаются в северо-западном направлении, хотя измерения на метеостанции г. Искитима фиксируют преобладание юго-западных и южных ветров. Возникшее противоречие объясняется орографическими особенностями местности, наличием возвышенных форм рельефа в правобережье р. Бердь и часто наблюдаемой устойчивой температурной стратификацией в нижней атмосфере. Конфигурация рельефа в данном случае оказывает заметное влияние на процессы распространения газовых и аэрозольных примесей в приземном слое атмосферы.

Отметим, что в условиях сложного рельефа данные измерений с близлежащей метеостанции могут не отражать реальное поле ветра в районе источника выбросов. Поэтому формальное использование общепринятой методики расчета полей концентраций примесей [14] может привести к ошибочным результатам и выводам. В связи с этим вытекает необходимость проведения также и мониторинговых исследований процессов техногенного загрязнения территорий.

\section{Заключение}

При традиционном подходе последовательные спутниковые снимки в период интенсивного снеготаяния позволяют выявить зоны загрязнений от промышленных предприятий за зимний сезон [7, 9]. Такой подход существенно ограничивает возможности использования космической информации, получаемой в течение всего зимнего периода. На наш взгляд, для более полного применения космической информации целесообразно привлекать данные о текущих метеорологических условиях. Тогда в периоды отсутствия снегопадов можно оценивать зоны промежуточного техногенного загрязнения. В частности, на территориях, находящихся под влиянием сибирского антициклона, в зимнее время при отсутствии облачности с помощью спутниковых снимков можно отслеживать ореолы загрязнений, формирующихся в периоды времени от нескольких дней до нескольких недель в окрестностях промышленных предприятий.

\section{Список литературы}

[1] Атмосферная турбулентность и моделирование распространения примесей. Под ред. Ф.Т.М. Ньистада и Х. ван Допа. Л.: Гидрометеоиздат, 1985. 351 с. [Atmospheric Turbulence and Air Pollution Modelling. Ed. by F.T.M. Nieuwstad and H. Van Dop. Leningrad, Gidrometeoizdat, 1985, 351 p. (in Russian)]

[2] Алоян А.Е. Моделирование динамики и кинетики газовых примесей и аэрозолей в атмосфере. М.: Наука, 2008. 415 с. [Aloyan A.E. Modeling of dynamics and kinetics of gas impurity and aerosols in the atmosphere. Moscow, Nauka, 2008, 415 p. (in Russian)]

[3] Берлянд М.Е. Современные проблемы атмосферной диффузии и загрязнения атмосфеpbl. Л.: Гидрометеоиздат, 1975. 448 с. [Berljand M.E. Modern problems of atmospheric diffusion and pollution of the atmosphere. Leningrad, Gidrometeoizdat, 1985, 448 p. (in Russian)] 
[4] Балтер Б.М., Балтер Д.Б., Егоров В.В., Стальная М.В. Использование данных ИСЗ LANDSAT для определения концентрации загрязнителей в шлейфах от продувки газовых скважин на основании модели источника. Исследование Земли из космоса, 2014, 2, 55-66 [Balter B.M., Balter D.B., Egorov V.V., Stalnaya M.V. Fitting the Emission Model and Meteorology to Landsat Data on Pollutant Plumes from Gas Well Pumping. Research of Earth from space, 2014, 2, 55-66 (in Russian)]

[5] Курбанов Э.А., Воробьёв О.Н., Лежнин С.А., Полевщикова Ю.А. Оценка загрязнения древостоев отходами силикатного производства по снимку RapidEye. Современные проблемы дистаниионного зондирования Земли из космоса, 2013, 10(2), 88-97 [Kurbanov E.A., Vorobyev O.N., Lezhnin S.A., Polevshikova Y.A. Estimation of forest contamination by the waste of silicate production on RapidEye image. Sovremennye problemy distantsionnogo zondirovaniya Zemli iz kosmosa, 2013, 10(2), 88-97 (in Russian)]

[6] Василевич М.И., Щанов В.М., Василевич Р.С. Применение спутниковых методов исследований при оценке загрязнения снежного покрова вокруг промышленных предприятий в тундровой зоне. Современные проблемь дистанционного зондирования Земли из космоса, 2015, 12(2), 50-60 [Vasilevich M.I., Shchanov V.M., Vasilevich R.S. Application of satellite methods to assess snow cover pollution around industrial enterprises in the tundra zone. Sovremennye problemy distantsionnogo zondirovaniya Zemli iz kosmosa, 2015, 12(2), 50-60 (in Russian)]

[7] Прокачева В.Г., Усачев В.Ф. Снежный покров как индикатор кумулятивного загрязнения в сфере влияния городов и дорог. Метеорология и гидрология, 2013, 3, 94-106 [Prokacheva V.G., Usachev V.F. Snow cover as an indicator of cumulative anthropogenic pollution induced by cites and roads. Meteorology and Hydrology, 2013, 3, 94-106 (in Russian)]

[8] Онучин А.А., Буренина Т.А., Зубарева О.Н., Трефилова О.В., Данилова И.В. Загрязнение снежного покрова в зоне воздействия предприятий Норильского промышленного района. $\mathrm{Cu}$ бирский экологический журнал, 2014, 6, 1025-1037 [Onuchin A.A., Burenina T.A., Zubareva O.N., Trefilova O.V., Danilova I.V. Snow Pollution in the Norilsk Indusrial Areal. Sibirskiy ekologicheskiy zhurnal, 2014, 6, 1025-1037 (in Russian)]

[9] Василенко В.Н., Назаров И.М., Фридман Ш.Д. Мониторинг загрязнения снежного покрова. Л.: Гидрометеоиздат, 1985. 182 с. [Vasilenko V.N., Nazarov I.M., Fridman C.D. Monitoring zagriyzneniy snezhnogo pokrova. Leningrad, Gidrometeoizdat, 1985, 182 p. (in Russian)]

[10] Катаев М.Ю., Бекеров А.А. Обнаружение экологических изменений природной среды по данным спутниковых измерений. Оптика атмосферы и океана, 2014, 27(7), 652-656 [Kataev M.Yu., Bekerov A.A. Detection of ecological changes in the natural environment from satellite measurements. Optika Atmosfery i Okeana, 2014, 27(7), 652-656 (in Russian)]

[11] Щербатов А.Ф., Рапута В.Ф., Турбинский В.В., Ярославцева Т.В. Оценка загрязнения атмосферного воздуха пылью по данным снегосъёмки на основе реконструкции полей выпадений. Анализ риска здоровью, 2014, 2, $42-47$ [Sherbatov A.F., Raputa V.F., Turbinskiy V.V., Yaroslavtceva T.V. Assessment of air pollution by dust according to data obtained from snow survey on the base of fall areas reconstruction. Health Risk Analysis, 2014, 2, $42-47$ (in Russian)]

[12] Рапута В.Ф. Численная реконструкция радиоактивного загрязнения местности от аварии на радиохимическом заводе в Томске-7. Оптика атмосферы и океана, 2012, 25(8), 733-737 [Raputa V.F. Numerical reconstruction of regional radioactive contamination by the 
accident at radiochemical plant in Tomsk-7. Optika Atmosfery i Okeana, 2012, 25(8), 733-737 (in Russian)]

[13] Рапута В.Ф., Шлычков В.А., Леженин А.А., Романов А.Н., Ярославцева Т.В. Численный анализ данных аэрозольных выпадений примесей от высотного источника. Оптика атмосферы и океана, 2014, 27(8), 713-718 [Raputa V.F., Shlychkov V.A., Lezhenin A.A., Romanov A.N., Yaroslavtseva T.V. Numerical analysis of aerosol substance fallout from a high-altitude source. Optika Atmosfery i Okeana, 2014, 27(8), 713-718 (in Russian)]

[14] Методика расчёта конщентраций в атмосферном воздухе вредных веществ, содержащихся в выбросах предприятий. ОНД-86. Под ред. М.Е. Берлянда, Н.К. Гасилиной, Е.Л. Гениховича и др. Л: Гидрометеоиздат, 1987, 94 с. [Metodika rascheta koncentracii v atmosfernom vozduhe vrednih vechestv, soderzhachihsiy v vibrosah predpriytii. OND-86. Ed. by M.E. Berljand, N.K. Gasilinoi and E.L. Genihovicha. Leningrad, Gidrometeoizdat, 1987, 94 p. (in Russian)] 